\title{
Considerations on the interference of mourning work in some memory problems
}

\begin{abstract}
Considering the practice in the clinic with the elderly we can perceive the frequency of the number of complaints of memory problems. We also observe that sometimes the environment of mourning may favor the emergence of certain forgetfulness. Given this, we will address something about the complexity involved in the grieving process and how such an environment can favor the emergence of forgetfulness.
\end{abstract}

Keywords: forgetfulness, mourning, elderly
Volume 3 Issue 2 - 2018

\section{Ester Benedita Santos Cavalcante \\ Postgraduate Psychologist at the Multiprofessional Residency in Health of the Elderly, State University of Rio de Janeiro, Brazil}

Correspondence: Ester Benedita Santos Cavalcante, Postgraduate Psychologist at the Multiprofessional Residency in Health of the Elderly, State University of Rio de Janeiro, State of Rio de Janeiro, Brazil.Email ester_ibalov@hotmail.com

Received: March 24, 2018 | Published: April |3, 2018

\section{Introduction}

From the praxis as a psychologist residing at the Multiprofessional Residency in Health of the Elderly at the State University of Rio de Janeiro, many issues could be relaunched. This practice takes place through a multiprofessional and interdisciplinary team, seeking integral care of the patient. Among the many important questions that arise in the clinic with the elderly, a subject that attracts a great deal of attention is the great number of complaints of "lack of memory". Due to the relevance of this subject, we need to reflect on the most varied issues that arise in these cases.

\section{Discussion}

Complaints about forgetfulness episodes and concerns about what may be causing them are very common in the clinic with the elderly. Regardless of the existence of any diagnostic that to indicate a dementia process, this question is posed. There are often certain stigmas that forgetfulness presented in the elderly may necessarily point to the aging of the brain.

In his text "About amnesia, or better, memory", Groisman contextualizes the increase of Alzheimer's diagnoses (the main symptom is the progressive loss of memory) in the 1980s and indicates that this decade was denominated by the World Health Organization (WHO) as the "brain decade". Therefore, in a context where Alzheimer's disease was "rediscovered " and the current paradigm was cognitive, the etiology of certain diseases was delegated to the brain increasingly.

We know that diagnosing diseases such as Alzheimer's, for example, is not so simple. In these cases, many investigations are necessary, being essential, including, the differentiation of certain depressive states and some process of dementia. ${ }^{2}$ In this context, where many doubts about the diagnosis are placed and where a greater evaluation is necessary, the coordination with psychology has a great importance. We Know that in many cases the forgetfulness is caused by organic issues. Sometimes, however, the causes can be subjective. Often these recurrent forgetfulness can occur in an environment marked by sadness due to significant losses in old age. ${ }^{3}$

Castilho $^{3}$ also points out that such complaints, related to episodes of forgetfulness, often present in an environment of mourning. In these cases, we must pay attention to the complexity of the situation that is being experienced. In such a situation of loss, the attention of the subject will be directed to the process of mourning, and may thus favor episodes of forgetfulness.

In "Mourning and Melancholy" Freud ${ }^{4}$ indicates mourning as a normal reaction to the loss of an object. He describes it as follows: " Mourning in general, is the reaction to the loss of a loved one, to the loss of some abstraction that has taken the place of a loved one, like the country, freedom or the ideal of someone, and so on. ${ }^{4}$

Thinking about the issue of mourning in the clinic with the elderly has a great relevance. Because, as Mucida ${ }^{5}$ indicates, "there is no old age without mourning". The entrance into old age can be marked by many changes and impose various losses. Although losses can occur at any age, we know that they occur more frequently for the elderly. Are innumerable examples of changes that such an era imposes: retirement, body changes, the loss of many people of his generation, among others. Mucida ${ }^{5}$ points out that one of the possible responses to so many losses and successive griefs may be depression. It is important to note, however, that although depression is a possible answer to so many losses without elaboration, it is not the only one. The environment of mourning may favor the appearance of other events such as certain forgetfulness, for example. The subject can respond in several ways, we should always consider the particularity of each situation.

\section{Conclusion}

It is possible to perceive that one of the specificities of the clinic with the elderly is the frequency of the losses to which they are exposed. Such losses require work of mourning, which is not easy ever, and it can often opening some way to the appearance of some symptoms. Such answers to these situations will always be singular, but as we have pointed out before, such an ambient of mourning may favor the emergence of certain forgetfulness. We know that complaints of "memory problems" are frequent in the clinic with the elderly, however, we must be warned that instead of a demential syndrome, subjective issues may play a role in some episodes of forgetfulness.

\section{Acnowledgements}

None. 


\section{Conflict of interest}

Author declares that there is no conflict of interest.

\section{References}

1. Groisman D. About Amnesia, or rather, memory. In: Verônica AS, Marilda SM; Ana LSM. editors. Art and health: adventures of the look. 1st edition. Rio de Janeiro: EPSJV; 2013:102 / 3.

2. Paradela EMP. Depression in the elderly. In Pedro Ernesto University Hospital Magazine, Rio de Janeiro. 2011;10(2).
3. Castilho G. About a complaint of "memory problems" in old age: Signorelli and Acropolis. School Letra Freudiana. 2015.

4. Freud S. Grief and melancholy. Brazilian standard edition of the complete works of sigmund freud. Vol. XIV. Rio de Janeiro: Imago; 1996.

5. Mucida A. The subject does not age - psychoanalysis and old age. Belo Horizonte: Authentic; 2007. 